\title{
Reduce deposits on heat exchange surfaces when burning inferior coal
}

\author{
Marin Bică ${ }^{1},{\text { Andrei } \text { Stoian }^{2}, \text { Dragoș Tutunea }^{1}, \text { Mădălina Călbureanu }}^{{ }^{*}}$ \\ ${ }^{1}$ University Of Craiova, Faculty of Mechanics, Romania \\ ${ }^{2}$ Turceni Thermal Plant, Romania
}

\begin{abstract}
The phenomenon of soiling of heat exchange surfaces occurs in all types of combustion plants. The deposit of solids (combustion gases particles) worsens heat transfer by reducing combustion efficiency, increasing fuel consumption and pollution. Deposits are influenced by combustion temperature, gas flow rate, dimensions of solids drift by combustion gases as well as the composition of fuel mixtures used (eg inferior coal with flame retardant gas or tar fuel). In the present paper are presented techniques and methods adopted for the reduction of soiling of the heat exchange surfaces and the results obtained on high energy power plants (steam boilers). Key words: deposits, heat exchange, combustion temperature, inferior coal.
\end{abstract}

\section{General considerations}

The conditions in the combustion plants vary greatly - from relatively cold temperatures to temperatures above $1500^{\circ} \mathrm{C}$ in the radiant part of the boiler and above $1800^{\circ} \mathrm{C}$ inside the flame. The dimensions of the solid particles trained by the combustion gases can also vary from less than one micron to a few millimeters in diameter.

The shape and consistency of the particles vary - depending on the equipment and the fuels - from spherical shapes to very irregular shapes and from solids to fluids. The deposits formed on the heat exchange surfaces have the effect of reducing the heat transferred to the working fluid.

The dirty area of the combustion heat exchanger parts is recorded in all areas of the industry. Wherever heat is transferred from the burnt gas stream containing corrosive or reactive particles, the accumulation of deposits on the exposed surfaces, not only on the surfaces of the heat exchangers, can cause problems.

As a result, unwanted solids build-up can occur on pipes or fittings in equipment such as dryers or reactors, as well as in combustion chambers and chimneys.

Expansion of harmful effects depends on a multitude of factors. The operating temperature, fluid velocities, particle sizes and the concentration of any solid substances entrained in the

\footnotetext{
* Corresponding author: Mădălina Călbureanu, madalina.calbureanu@gmail.com
} 
gas stream, as well as the chemical composition of components in the fuel mixture, are liable to cause the soiling of the heat exchange surfaces.

The presence of deposits on the surfaces of the heat exchangers will prevent an efficient heat transfer that will affect the efficiency of the whole plant. In addition, unwanted accumulation of deposits on structures may cause mechanical damage that may result in unscheduled shutdowns (damages). They lead to decreases in production and increased maintenance costs.

\section{Formation of deposits mechanisms}

In an attempt to understand the effects of different deposit variables in a combustion system, it is useful to have a general understanding of the mechanisms involved, so that the needs and requirements for a good design and operation of the equipment can be appreciated.

The mechanisms involved will vary depending on the type of deposit particles, vapor diffusion or chemical reaction.

It is convenient to analyze these mechanisms separately, although they will rarely appear isolated, and some interactions, to a greater or lesser extent, occur in industrial conditions. In this research a model for the growth of the deposition layer has not been achieved. It will be a concern in future research.

\subsection{Molecular diffusion}

It is the result of the individual and disordered displacement of molecules, determined by the movement of thermal agitation and elastic collisions with the other molecules in a mixture of several molecular species. Molecular diffusion is therefore a mechanism that occurs at the molecular level and consists in transporting a molecular species within a mixture when there is a potential difference in the mixture, which produces an imbalance within the mixture.

The potential difference can be determined by several causes:

- the existence of a concentration gradient in the mixture - which causes a Fick diffusion;

- the existence of a temperature gradient in the mixture - which causes a thermal diffusion;

- the existence of a mixture pressure gradient - which causes a pressure diffusion.

\subsection{Vapor diffusion}

The transport of particles to heat exchanging surfaces in a combustion system may result from the vaporization of the inorganic components of the ash and their subsequent diffusion to the surfaces of the equipment. Flame-breaking of inorganic components is the usual origin of these vapors. Generally, the diffusion principles (except for inertial collision) will apply to the molecules of these vapors, but some significant consequences may result from the temperature gradients existing in the equipment. Vapor diffusion from warmer areas to cooler areas can be changed in stages, from vapor to liquid droplet and ultimately to solid particles. The conditions are illustrated in Figure 1. 


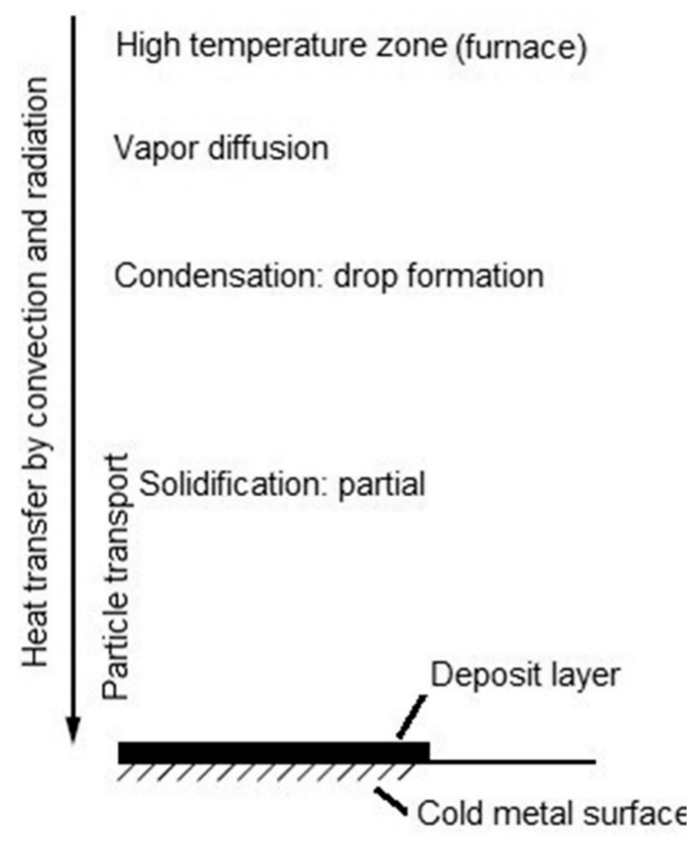

Figure 1. Changing the phases along the temperature gradient in the combustion chamber

The location of the various areas, as they are presented very generally in the above figure, will undergo a permanent change. Because of the change in temperature, the distribution increases as the thickness of the deposit layer. Due to these temperature changes, the vapor and drip areas will move to the cold area, which, after the accumulation process has begun, will be the outer layer of the deposit. If deposition was due only to vapor diffusion, the deposition thickness becomes asymptotic over time since the outer layer is above the dew point.

Phase change can lead to amplification of other effects such as:

- droplet fusion

- agglomeration of particles during transport by cementation due to their sticky or melt state

- condensation of vapors either on the chiller's surfacees of the equipment or in the chiller's area.

\subsection{Chemical reactions}

Given the complexity of most fuels, such as fossil fuels and coal, or to a lesser extent household waste or biomass, the possibilities of chemical reactions are very high. The type of chemical reactions is influenced by the conditions in the combustion plants.

\section{Cleaning of heat exchange surfaces}

In most combustion systems, the phenomena of dirt and grease are likely to occur and steps must be taken to restore the efficiency of the heat exchange surfaces to or near the project values. 
There are a number of techniques and technologies used to clean these surfaces. They can be divided into two large groups:

- $\quad$ hot cleaning tehniques and tehnologies (during the operating installation)

- cold cleaning techniques and tehnologies (wth the equipment off)

To facilitate cleaning, additives are used. In coal-fired combustion plants the use of an additive can lead to the transformation of deposits so that they are suitable for a hotstripping method, or if the accumulations are high that it is necessary to stop the plant, the use of additives during operation may reduce the time necessary for cold cleaning operations.

\subsection{Cleaning during plant operation}

The purpose of this cleaning method is to keep the heat exchange surfaces in a reasonable state of cleanness to ensure efficiency and operation in the plant's parameters. Hot soot removal processes use soot blowing or chemical cleaning processes.

\subsection{Soot blowing}

Most soot blowers are rotating and retractable in length. Rotary blowers use multidirectional elements able to rotate so that the depositing layer can be removed with a jet spring.

Steam blowers are mainly used in the area of superheaters.

Air blowers. Air use requires a separate system with compressor and water jets. It achieves a considerably higher amount of deposition than the use of air or steam. In addition, there is a hardening effect on hot deposition that leads to fracture of the deposition and breakage of its bond with the heat exchange surface. These effects make it easier to remove deposits. Unwanted effects also occur: large pieces of slag that can damage the heat exchange surfaces may occur.

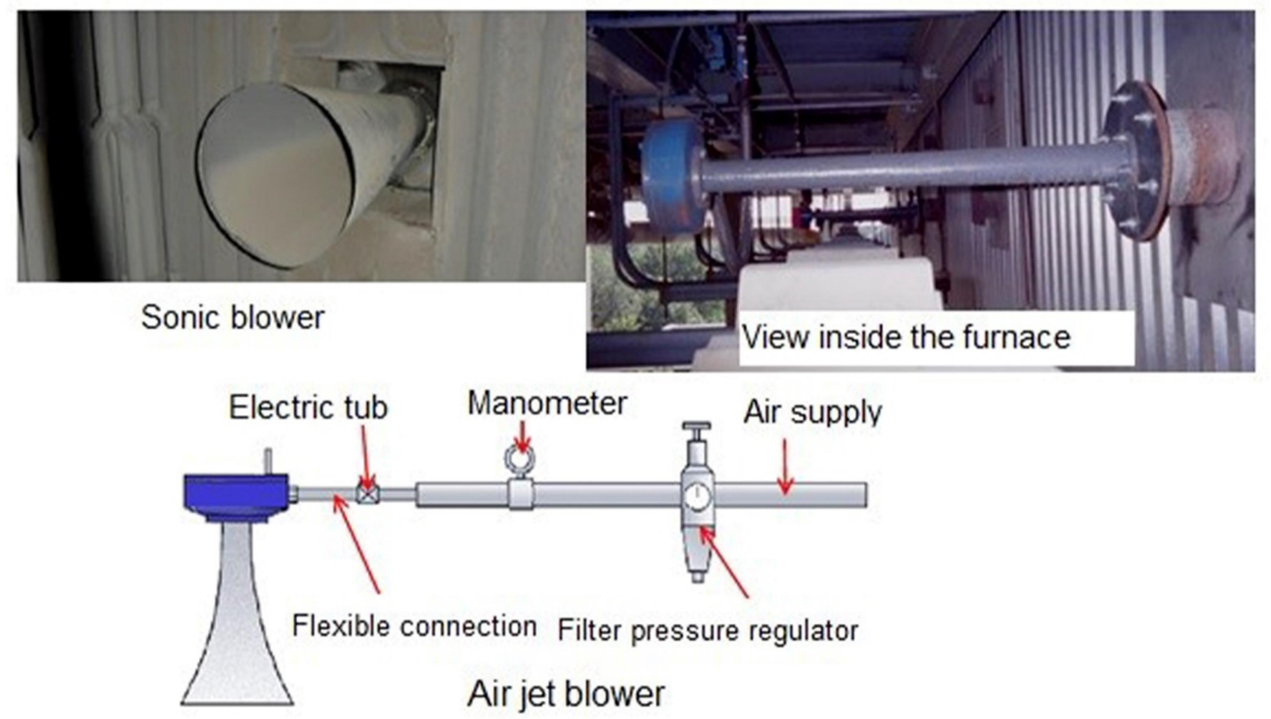

Figure 2 Types of blowers 
Multijet blowers are also used to clean the cold parts of the plant, convective parts, extended surface economisers and regenerative preheaters. Where high temperatures are recorded, it may be necessary to use the air to cool the various components of the blower. High or low frequency sounds are used to clean the dirty surfaces of heat exchangers special attention should be paid to low-frequency sounds.

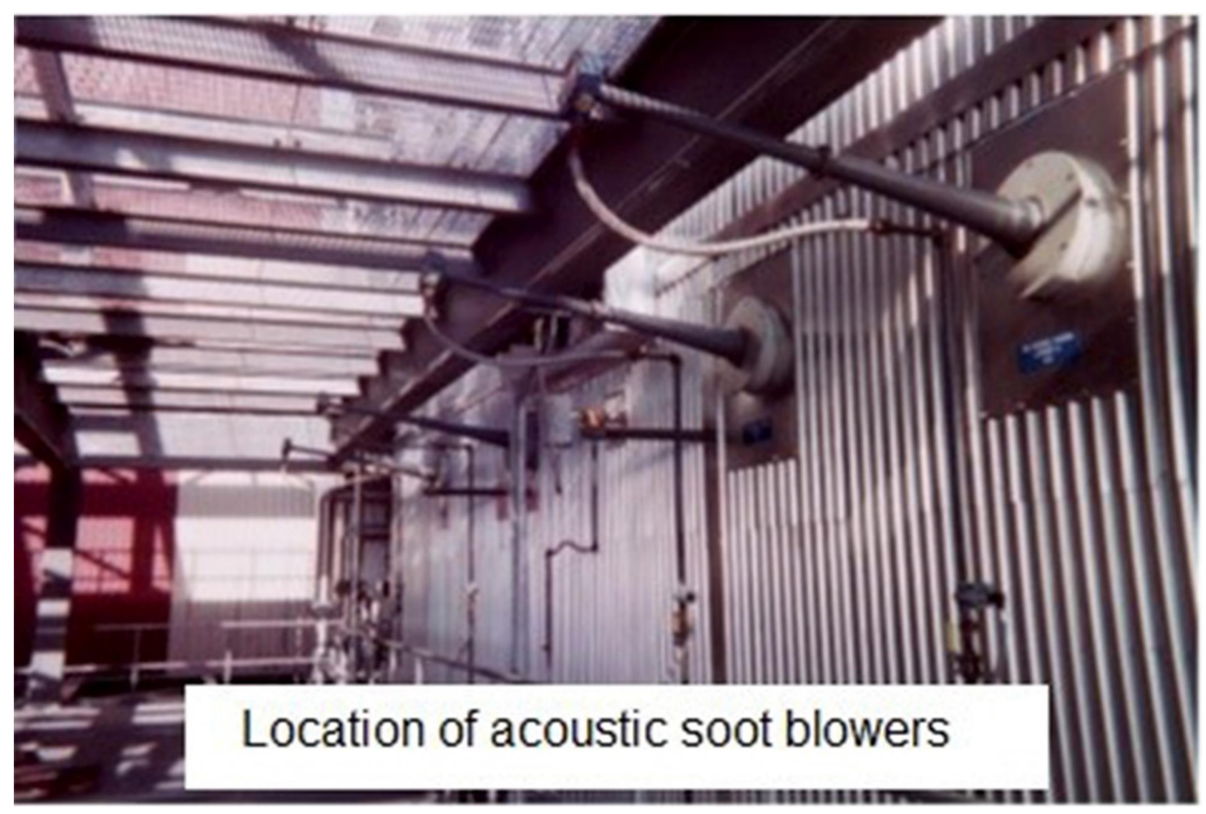

Figure 3 Acoustic soot blowers

Sonic blowers are not very effective for hard deposits, but are useful for loose, soft deposits. Unlike steam or air blowers, sonic cleaning devices are being used more and more frequently lately. The operating costs of the audio devices are usually lower than those of traditional devices.

\subsection{Shot cleaning of the deposits}

Shot cleansing uses the kinetic energy of the shots to dislodge deposits. Technology involves "bombarding" surfaces that need to be cleaned with metallic shots or made of other material. The basic principle of using this technology is not the cleaning of deposits and especially the prevention of their formation.

Cleaned surfaces should be inspected periodically to see if damage has occurred due to shots. In case of such damage, it is necessary to reposition the distribution system or to apply protective shields.

\subsection{Chemical cleaning}

Chemical cleaning during operation or after stopping is routinely used. Hot cleaning is done by spraying on the deposit's surface chemicals that remove them from the chemical reactions that take place. There may be problems with equipment caused by thermal shocks. Cleaning after stopping is more efficient and presents a lower risk of damage to the structure. Gas ammonia and steam have been successfully used. 


\subsection{Cold cleaning}

The cleaning methods described below are those that can be applied when the combustion equipment is switched off either for routine maintenance or especially when cleaning is required as a result of reducing the plant's operating load.

It provides a good opportunity to clean the plant and allows a visual inspection to verify the results of cleaning techniques applied to determine if cleaning causes degradation of heat exchange surfaces.

\subsection{Dry cleaning}

Completely dry cleaning by manual or mechanical means should be used if cleaning of the heat exchange surfaces with water or steam is not possible or is considered inappropriate. Manual dry cleaning is an activity involving a lot of dust and many hazards, so special precautions must be taken.

An alternative method to manual dry cleaning is dry cleaning by blasting or sanding. It is necessary to have enough space under the equipment to collect both the shots and the dislocated deposits.

Manual or mechanical dry cleaning can be supplemented by using compressed air lances or by suction equipment.

\subsection{Washing}

Water washing can be an effective way of eliminating unwanted deposits. The cleaning technique applies to the entire system with large amounts of water. Washing can be done by spraying or by pressure water jets. Adding wetting agents or detergents can improve the washing process.

\subsection{Steam cleaning}

This technology involves the intake of steam into the combustion gas space in contact with the surfaces that have accumulated deposits. To protect the system, it will be necessary to fill the heat exchanger pipes with cold water. Frequent site inspections are also required. Problems caused by corrosion of metal parts can be encountered. For the intake of steam it is necessary to build special installations, but the existing blowers are usually used.

\section{Conclusions}

The boilers of the Turceni Thermal Power Plant have cleaned the heat-exchange surfaces by several processes. It has been found that on the heat exchange surfaces of the flue gas path of deposits with variable thicknesses which can not be completely removed by mechanical cleaning or washing, respectively:

- in the furnace, in the upper part - hard deposits on boiling pipes very difficult to remove by mechanical cleaning;

- on the S3 pipes - heavy deposits difficult to remove by mechanical cleaning;

- on the SI 2 pipes - dust-like deposits, relatively easy to remove by mechanical cleaning;

- to rotary air preheaters (PAR) - hard deposits containing sulfur compounds, difficult to remove by washing with water jet under pressure. 


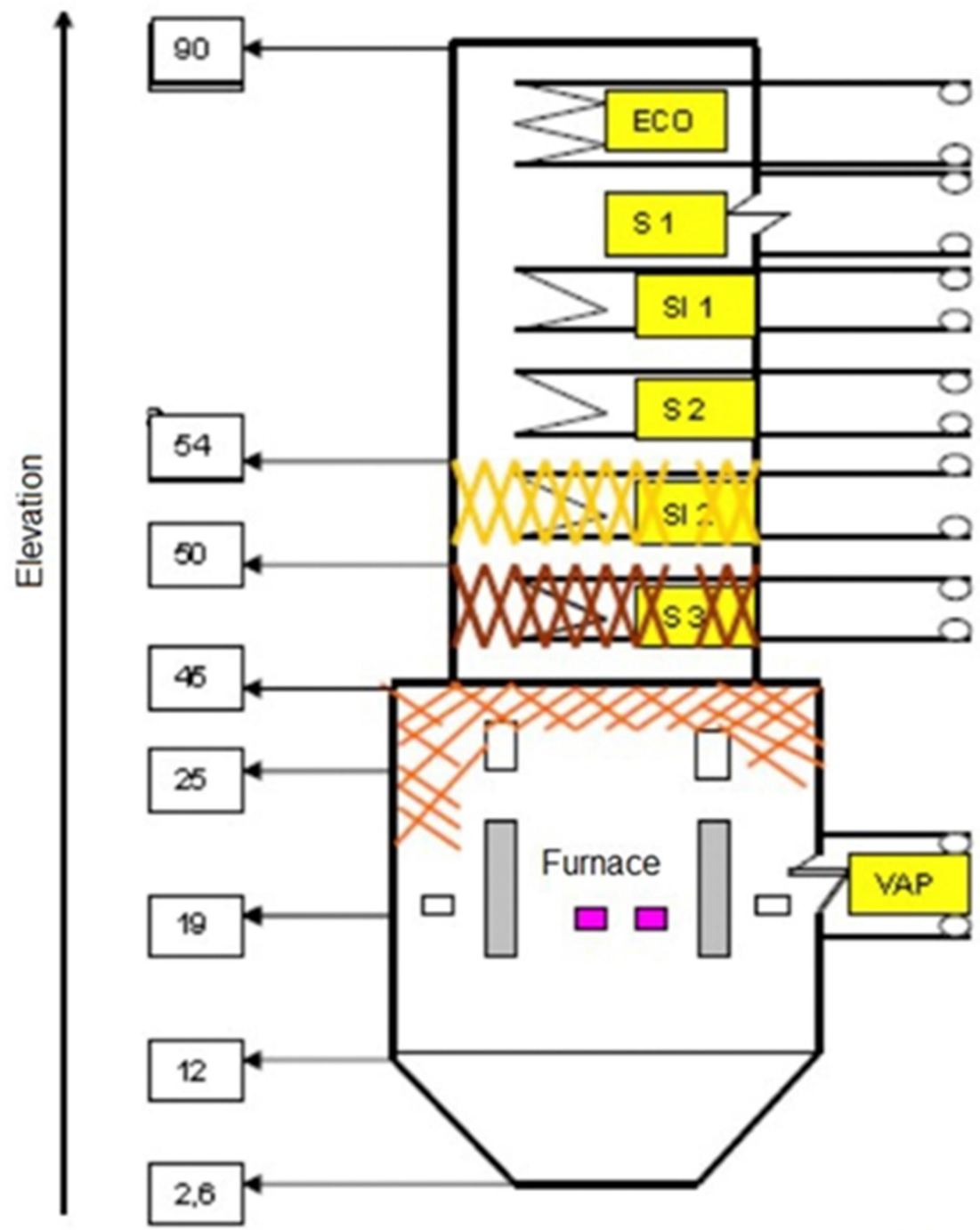

Figure 4. Benson type tower with forced circulation and flow rate of 1035 tones $/ \mathrm{h}$

In the experimental researches, the THERMA-CHEM (UK license) technology was used to clean and reduce the pollutant emissions, which ensured the following goals during the boiler operation:

- Reduction / elimination of deposits on the heat exchange surfaces located on the flue gas path and implicitly improvement of the heat exchange;

- Reduce fuel consumption, increase efficiency and load availability of the boiler,

- Improving the boiler and combustion process by eliminating the unburnt material,

- Reduction of low temperature corrosion (acidic corrosion),

- Reduction of emissions into the environment of: $\mathrm{NOX}, \mathrm{SO} 2, \mathrm{SO} 3, \mathrm{CO}$ and $\mathrm{CO} 2$. 


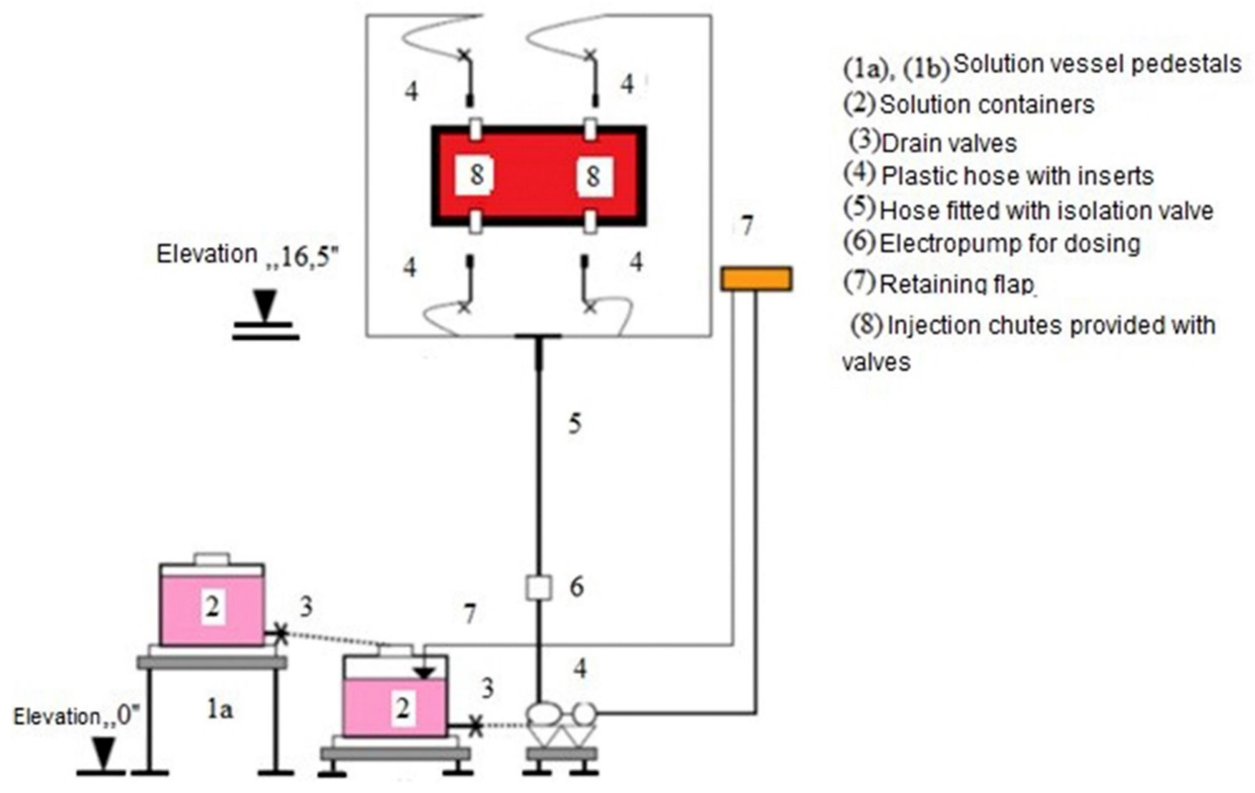

Figure 5 Schematic diagram of the cleaning installation

The benefits of cleaning the heat exchange surfaces are obvious: exemplified by the graphs for recording the temperature of the combustion gases before and after cleaning.

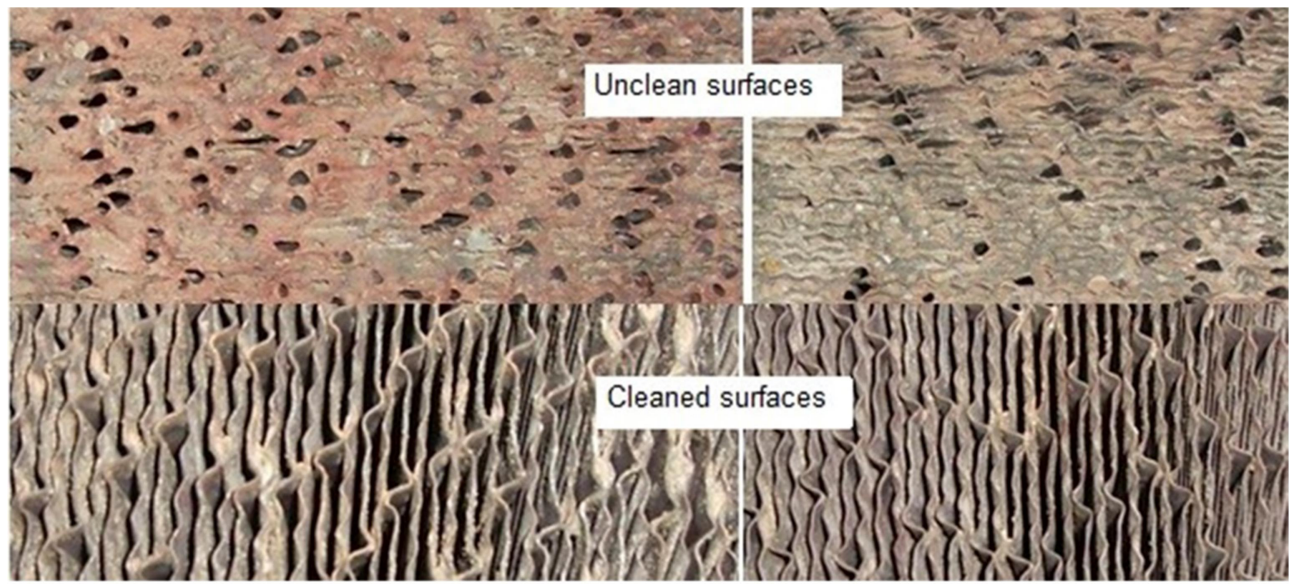

Figure 6. Surface condition before and after cleaning 


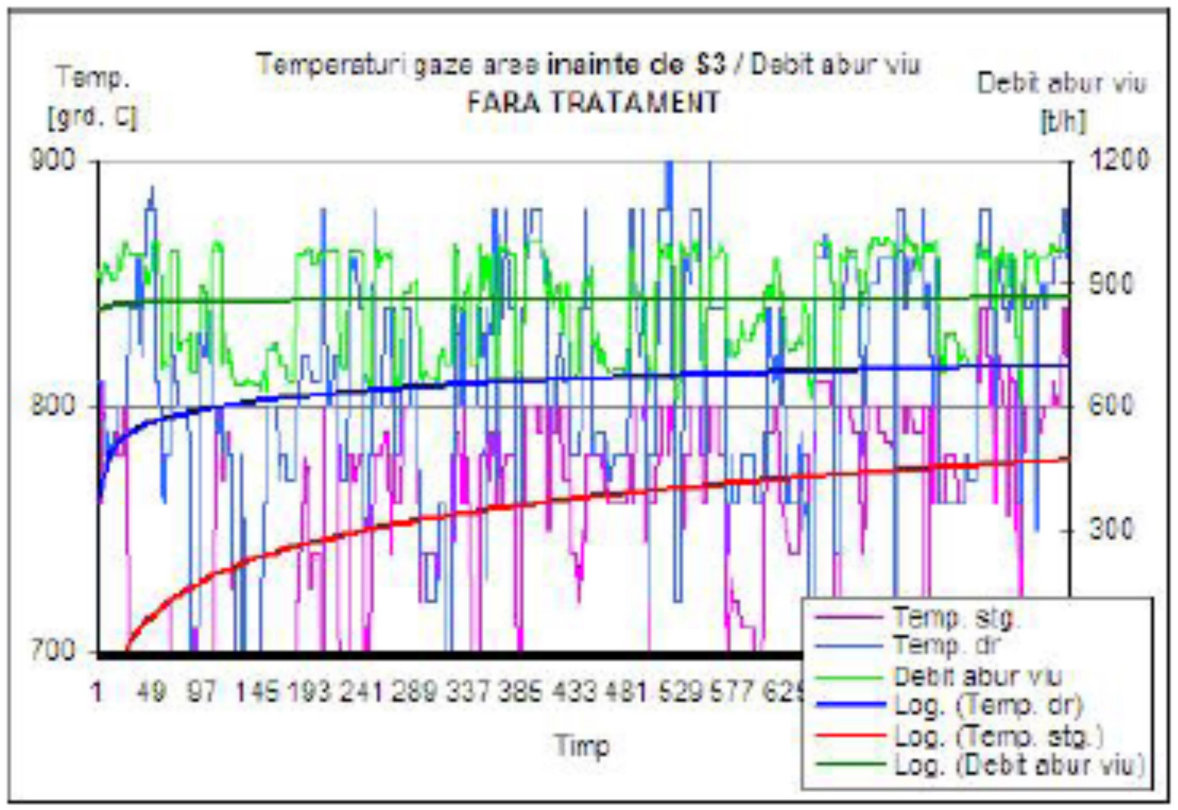

Figure 7. During the period prior to the cleaning in the combustion chamber, at a relatively constant load, the temperature of the combustion gas has a ASCENDING evolution, indicating a worsening of the heat exchange over time as a result of soiling of the heat exchange surfaces through the appearance of the slag deposits.

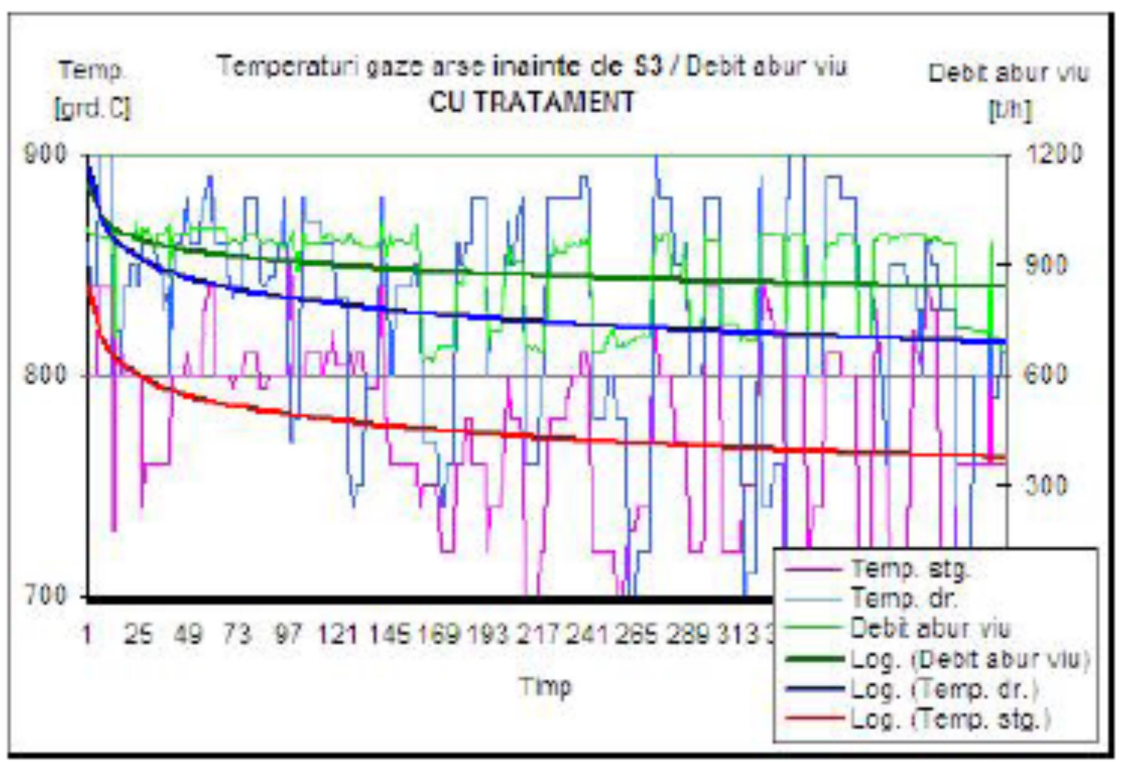

Figure 8. In the period after cleaning in the enclosure, under the same operating conditions, the temperature of the combustion gas has a DESCENDING evolution, indicating an improvement in heat exchange over time due to the removal of deposit deposits (by eliminating in particular unbound carbon, which constitutes generally the element with the largest insulating properties) and their partial elimination. 
A simple calculation made at the Turceni Thermal Power Plant:

- considering an increase in efficiency of only $1 \%$ (corresponding to the reduction of the temperature to the chimney), it results a saving of 1620 USD / day:

$1 \%$ x 400 tonnes / h lignite $\times 24 \mathrm{~h} /$ day $\times 15$ USD / lignite tonne $=1440$ USD / day.

$1 \%$ x $5000 \mathrm{Nm} 3 / \mathrm{h} \times 24 \mathrm{~h} /$ day $\times 150 \mathrm{USD} / 1000 \mathrm{Nm} 3=180 \mathrm{USD} /$ day

- reduction of injections, mean with approx. 20 - $40 \mathrm{~kg}$ of water / $1 \mathrm{t}$ of live steam in overheaters for steam temperature control has the effect of improving the boiler efficiency by $0.5-1 \%$, resulting savings of approx. $800-1600$ USD / day.

\section{References}

1.D. Ștefănescu, A. Leca, Transfer de caldura si masa, Editura didactica si pedagogica, Bucuresti, (1983)

2.M. Bică, Bazele termotehnicii si masini termice, Universitatea din Craiova, (1996)

3.A. Leca, s.,a., Transfer de caldura si masa, Editura tehnica, Bucuresti, (1988)

4.M. Bică, M. Naghi, Transfer de caldura si masa, Editura Universitaria, Craiova (1999)

5.Manualul inginerului. Termotehnica, Editura tehnica, Bucuresti, (1986)

6.R. Vilcu, Termodinamica chimica, Editura tehnica, Bucuresti, (1985)

7.M. Bică, Termotehnică şi maşini termice, Editura Universitaria Craiova, (2000)

8. M. Motocu, V. Bănică, L. Danciu, V. Osiac: Optimizarea activitatii termocentralei Turceni în concordanţă cu standardele de mediu, Revista Energetica, iulie (2005), ISSN 14353-2365.

9.K. Schroder, Centrale electrice de mare putere, Editura tehnica, Bucuresti, (1974)

10.A.I. Reynolds, Curgeri turbulente in tehnica, Editura tehnica, Bucuresti, (1982)

11.ESDU Fouling in cooling systems using seawater. ESDU 03004, ESDU

International plc, London, UK, (2003).

12. ESDU Fouling in cooling systems using freshwater. ESDU 06017, ESDU International plc, London, UK, (2006). 